\title{
ASSESSMENT OF HEAVY METAL REMOVAL EFFICIENCIES BY NATURALLY FERMENTED AND $A$. NIGER FERMENTED PINEAPPLE WASTES FROM CONTAMINATED SEWAGE SLUDGE
}

\author{
Dominica del Mundo Dacera \\ Sandhya Babel \\ Sirindhorn International Institute of Technology (SIIT) \\ Thammasat University, Thailand
}

\begin{abstract}
Heavy metals in sewage sludge can pose a long term environmental risk due to their toxicity, non-biodegradability and consequent persistence. This study assessed the efficiencies of various organic extractants such as naturally fermented and Aspergillus niger (A. niger) fermented raw liquid from pineapple wastes, in the chemical extraction process, to extract $\mathrm{Cr}$, $\mathrm{Cu}, \mathrm{Pb}, \mathrm{Ni}$ and $\mathrm{Zn}$, from anaerobically digested sewage sludge in Thailand. Pineapple wastes are a good source of sugar and protein and have been utilized experimentally in the production of citric acid by fermentation with the fungus $A$. niger. Comparison of the extraction efficiencies of these extractants with commercial citric acid was also investigated at two hours leaching time and $\mathrm{pH} 3$ and greater. Results of the study revealed that at $\mathrm{pH}$ approaching $4, A$. niger fermented liquid seemed to exhibit the best removal efficiency for practically all metals studied, attaining as much as $72 \%$ removal for $\mathrm{Zn}, 70 \%$ for $\mathrm{Ni}, 50 \%$ for $\mathrm{Cr}$ and $37 \%$ for $\mathrm{Cu}$, although effectivity of removal seemed to be less apparent for $\mathrm{Pb}$. The most readily solubilized metal seemed to be $\mathrm{Zn}$ with the most removal of $92 \%$ attained by naturally fermented raw liquid. The effectivity of removal by $A$. niger fermented liquid may be due to the presence of citric acid and other carboxylic acids as confirmed by the HPLC and IR studies of the fermented liquid. Moreover, variation in metal removal efficiencies may be attributed to the forms of metals in the sludge, as evidenced by chemical speciation studies using sequential chemical extraction procedure, with metals predominantly in the exchangeable and oxidizable phases showing ease of leachability.
\end{abstract}

\section{KEYWORDS}

A. niger fermented liquid; Chemical extraction; Chemical speciation; Heavy Metals; Naturally fermented liquid; Pineapple wastes; Sewage sludge

\section{INTRODUCTION}

Wastewater treatment plant operations generate large amounts of residual sludge, which pose serious problem in their final disposal due to the presence of toxic substances such as heavy metals. It was reported that the total heavy metal content of wastewater (sewage) sludges is about $0.5-2 \%$ on a dry weight basis and in some cases may rise up to $4 \%$ on a wet weight 
basis, especially for metals such as cadmium $(\mathrm{Cd})$, chromium $(\mathrm{Cr})$, copper $(\mathrm{Cu})$, lead $(\mathrm{Pb})$, nickel $(\mathrm{Ni})$ and zinc $(\mathrm{Zn})[1,2]$. One of the various technologies used in the extraction of heavy metals from contaminated sewage sludge is chemical extraction. The extraction process involves solubilization of heavy metals in sludge via acidification, followed by separation of solids from the liquid through the dewatering step of the sludge handling process. After extraction, removal of heavy metals from the extracting agents can be accomplished by chemical sulphide precipitation and selective ion-exchange [3].

Among the extracting agents used in the chemical extraction process, citric acid, has been found to be promising, since extraction can be performed at mildly acidic condition ( $\mathrm{pH} 3-4$ ) with relatively high efficiency of metal removal. Moreover, the citric acid, being organic, is readily degradable under aerobic and anaerobic conditions [3, 4, 5,]. Citric acid $\left[\mathrm{C}_{3} \mathrm{H}_{5} \mathrm{O}(\mathrm{COOH})_{3}\right]$, is a 6-carbon containing tricarboxylic acid and exists as an intermediate in the citric acid cycle when carbohydrates are oxidized to carbon dioxide. The acidic nature of citric acid results from the three carboxy groups $(\mathrm{COOH})$ which can lose a proton in solution forming the citrate ion. Citrates can chelate metal ions and therefore have been used as chelating and sequestering agents [6,7]. Citric acid is currently produced commercially by fermentation of sucrose using mutant strains of Aspergillus niger (A. niger), and chemical synthesis. Carbohydrates and wastes that have been considered experimentally to produce citric acid by $A$. niger include date fruit syrup, soya beans, cheese whey, pineapple wastes, corncobs and cane molasses $[8,9,10,11]$. Interest is directed toward pineapple solid wastes especially in Thailand where pineapple is one of the major food products in the country. It was reported that in 2002, fresh pineapple production in Thailand reached up to 2.0 million tons [12]. Since about $70-80 \%$ of the pineapple fruit is normally discarded as solid waste [11, 13] an equivalent of 1.4-1.6 million tons of pineapple solid wastes is also produced. Although some research have been conducted on the utilization of these wastes (such as for animal feed, alcohol, vinegar and wine production), this enormous quantity of discarded material has not been utilized efficiently. The wastes are still currently disposed of into the environment at a considerable cost for transportation and environmental degradation. Therefore, research on the alternatives for utilization of these wastes is still of interest.

This study investigated the efficiency of using naturally fermented (without $A$. niger) and $A$. niger fermented raw liquid from pineapple wastes in the extraction of $\mathrm{Cr}, \mathrm{Cu}, \mathrm{Pb}, \mathrm{Ni}$ and $\mathrm{Zn}$ from anaerobically digested sewage sludge, with commercial citric acid as a reference. Extraction efficiencies were observed at various $\mathrm{pH}$ conditions and two hours contact time. Chemical speciation studies were also done to determine the forms of metals in sludge which affects extraction efficiency.

\section{MATERIALS AND METHODS}

\subsection{Sludge characterization}

The sludge sample was taken from the sludge treatment facility at Nongkhaem, in Bangkok, Thailand, which receives dewatered sludges mainly from five central wastewater treatment facilities under the Bangkok Metropolitan Administration (BMA). This treatment facility employs anaerobic digestion for sludge treatment and uses filter press to dewater the treated sludge prior to disposal mostly by landfill. The BMA sludge sample collected was analyzed in terms of its physical and chemical characteristics, including heavy metals content according to the Standard Methods for the Examination of Water and Wastewater [14]. Heavy metals were analyzed using flame atomic absorption spectrophotometer (AAS Hitachi Z-8230) after 
microwave digestion (O.1. Analytical) with nitric acid $\left(\mathrm{HNO}_{3}\right)$, hydrofluoric acid (HF), hydrochloric acid $(\mathrm{HCl})$ and boric acid $\left(\mathrm{H}_{3} \mathrm{BO}_{3}\right)$.

\subsection{Chemical speciation studies}

Chemical speciation studies were done using the sequential chemical extraction (SCE) procedure by Del Mundo Dacera and Babel [4]. The sequential extraction was carried out in two grams air dried sludge samples in $250 \mathrm{ml}$ erlenmeyer flasks. Between each of the successive extractions, separation was done by centrifuging at $4,000 \mathrm{rpm}$ for 30 minutes where the supernatant was removed and analyzed for trace metals by flame AAS and the residue washed with $40 \mathrm{~mL}$ deionized water.

\subsection{Raw liquid extraction and analysis}

Pineapple waste samples were collected from a local fruit processing facility and consisted of the core, peel (shell), and top and bottom cuts. The wastes were then crushed, ground and squeezed manually with a fine cloth to separate the pulp from the raw liquid. The raw liquid was analyzed for total sugar using high performance liquid chromatography (HPLC-Agilent Technologies 1100) and total acidity as citric acid using the Glass electrode method following the AOAC Official Methods of Analysis [15]. Infrared Spectroscopy (Brucker Vector 22) was used to confirm the presence of citric acid as carboxylic acid in the raw liquid. The amount of citric acid extracted from $A$. niger fermented liquid was measured using high performance liquid chromatography (HPLC) with an Aminex HPX-87H column (Bio-Rad, Hercules, CA, USA) at $608 \mathrm{C}$, using $5 \mathrm{mM} \mathrm{H}_{2} \mathrm{SO}_{4}$ as a mobile phase at a flow rate of $0.6 \mathrm{~mL} / \mathrm{min}$. Citrate was detected refractometrically (Waters 410 Differential Refractometer Detector, Millipore Corp., Milford, MA, USA). The pulp, which is known to contain a high percentage of protein [11], can still be used as animal feed.

\subsection{Natural fermentation of raw liquid by shake flask studies}

Optimum conditions for raw liquid fermentation from pineapple wastes with $A$. niger by Sun [11], were adapted in this study. The raw liquid extracted from pineapple wastes was allowed to undergo aerobic fermentation in natural conditions (i.e. without $A$. niger) by shaking at 150 rpm for 144 hours ( 6 days) at $30 \AA \mathrm{e} C$. Samples taken from fermentation (fermented mash) was filtered to separate the solids from the filtrate. The filtrate was then used for leaching the BMA sludge samples. Total sugar and acidity analyses of the filtrate were done immediately in order to avoid decomposition.

\subsection{Raw liquid fermentation with $A$. niger}

\subsubsection{A. niger inoculum preparation}

The individual strain of $A$. niger obtained from BIOTEC Central Research Unit, Pathumthani, Thailand, was inoculated on potato dextrose agar slant (PDA) at $30 \AA \mathrm{C}$ for 7 days. Spore suspension was prepared by cultivating the strain in flasks containing 29-30 grams rice grain, with $6 \mathrm{~mL}$ sterilized medium (yeast, peptone, glucose or YPG) for 7 days at $308 \mathrm{C}$. The YPG contained the following: yeast extract $(5 \mathrm{~g} / \mathrm{L})$; peptone $(10 \mathrm{~g} / \mathrm{L})$ and glucose $(20 \mathrm{~g} / \mathrm{L})$. The resulting spores were harvested in $0.1 \%$ Tween 80 (Polyoxyethylene-sorbitan monooleate) solution and used to inoculate the raw liquid at $10^{9}-10^{10}$ spores per liter [16]. The prepared $A$. niger inoculum if properly stored, can be used several times for fermentation of the raw liquid.

\subsubsection{A. niger fermentation of raw liquid by shake flask studies}


Optimum conditions for raw liquid fermentation from pineapple wastes using $A$. niger by Sun [11], were also adapted in this study. Prior to fermentation, the raw liquid $(250 \mathrm{~mL})$ was dispensed into $1,000 \mathrm{~mL}$ erlenmeyer flasks. Since the initial $\mathrm{pH}$ of the raw liquid was 3.7, no $\mathrm{pH}$ adjustment was made to meet the $\mathrm{pH}$ requirement for citric acid fermentation which is 3-4. Phosphorus in the form of potassium dihydrogen phosphate $\left(\mathrm{KH}_{2} \mathrm{PO}_{4}\right)$ was added at the rate of $0.5-1.0 \mathrm{~g} / \mathrm{L}$. The flasks were autoclaved at $103.42 \mathrm{kPa}\left(15 \mathrm{lb}_{\mathrm{f}} / \mathrm{in}^{2}\right)$ at $121^{\circ} \mathrm{C}$ for 15 minutes prior to use. Each flask was inoculated with $2 \mathrm{~mL}$ spore suspension and was shaken at 150 rpm for 144 hours (6 days) at $30^{\circ} \mathrm{C}$. Samples taken from fermentation (fermented mash) were filtered to separate the mycelium from the liquid phase. The filtrate was then used for leaching the BMA sludge samples and analyzed for total sugar and citric acid immediately, in order to avoid decomposition. The mycelium, which is high in protein [11], can also be used as animal feed. The yield of mycelial dry weight was $28.2 \mathrm{~g} / \mathrm{L}$.

\subsection{Leaching Procedure for commercial citric acid, naturally fermented and $A$. niger fermented liquid from pineapple wastes}

The following acid leaching procedures modified from Marchioretto et al. [5] and Veeken and Hamelers [3], were used:

Samples containing two grams of air dried sludge were transferred to reactors and filled with $40 \mathrm{~mL}$ deionized water. Varying amounts of the extractants were then added to the sludge samples to obtain the desired $\mathrm{pH}$ of $3.04\left(1.4 \times 10^{-1} \mathrm{~g} / \mathrm{g}\right), 4.0\left(3.0 \times 10^{-2} \mathrm{~g} / \mathrm{g}\right), 5.01\left(4.2 \times 10^{-3} \mathrm{~g} / \mathrm{g}\right)$ and $6.0\left(5.3 \times 10^{-4} \mathrm{~g} / \mathrm{g}\right)$, for $0.1 \mathrm{M}$ commercial citric acid; $\mathrm{pH}$ of $3.67(46.6 \mathrm{~g} / \mathrm{g}), 3.82(3.0 \mathrm{~g} / \mathrm{g}), 4.02$ $(1.5 \mathrm{~g} / \mathrm{g}), 4.24(0.74 \mathrm{~g} / \mathrm{g})$ and $4.36(0.53 \mathrm{~g} / \mathrm{g})$, for naturally fermented liquid; and $\mathrm{pH}$ of 3.73 $(42.0 \mathrm{~g} / \mathrm{g}), 3.88(9.0 \mathrm{~g} / \mathrm{g}), 3.98(3.0 \mathrm{~g} / \mathrm{g}), 4.47(1.1 \mathrm{~g} / \mathrm{g})$ and $4.51(0.53 \mathrm{~g} / \mathrm{g})$, for A. niger fermented liquid. The $\mathrm{pH}$ measurements were done using Oakton pH 10 series (Model No. 35614-70). In order to ensure accuracy across the entire range of the meter, a 2-point calibration was done before each $\mathrm{pH}$ measurement. A rotary shaker (Panapolytech Sseriker II) was used to mix the reactors continuously at $150 \mathrm{rpm}$ at room temperature for $2 \mathrm{~h}$. After leaching, the samples were collected and centrifuged (Nuve NF 800) at 4,000 rpm for $30 \mathrm{~min}$ and then filtered using $47 \mathrm{~mm}$ glass microfibre filter $(1.2 \mu \mathrm{m} \mathrm{GF} / \mathrm{C})$. The filtrate was then analyzed for heavy metals $(\mathrm{Cr}, \mathrm{Cu}, \mathrm{Pb}, \mathrm{Ni}$ and $\mathrm{Zn})$ using flame AAS. After analysis, the $\mathrm{pH}$ values corresponding to the optimum acid dosages were determined.

\section{RESULTS AND DISCUSSION}

\subsection{Physicochemical characteristics of sludge}

The BMA dewatered sludge sample for this study was found to have an initial $\mathrm{pH}$ of 6.83 , total solids of $25 \%$, and organic matter content of $38.8 \%$ (as measured by total volatile solids). The total nitrogen of $1.53 \%$ and total phosphorus of $2.04 \%$ in the sludge, indicated its agricultural value. The sludge sample was found to contain the following heavy metals in $\mathrm{mg} / \mathrm{kg}$ dry matter (DM): $\mathrm{Cr}(404), \mathrm{Cu}(1,480), \mathrm{Pb}(106), \mathrm{Ni}(220)$ and $\mathrm{Zn}(1,775)$. Referring to the proposed BMA standards [17] for agricultural application of sludge, only $\mathrm{Cu}$ exceeds the standard of $900 \mathrm{mg} / \mathrm{kg} \mathrm{DM}$, with $\mathrm{Ni}$ and $\mathrm{Zn}$ approaching the standards of $400 \mathrm{mg} / \mathrm{kg} \mathrm{DM}$ and $3,000 \mathrm{mg} / \mathrm{kg} \mathrm{DM}$, respectively. The other metals seem to be below the standards of 1,000 $\mathrm{mg} / \mathrm{kg} \mathrm{DM}$ for $\mathrm{Cr}$ and $1,000 \mathrm{mg} / \mathrm{kg} \mathrm{DM}$ for $\mathrm{Pb}$. However, since the presence of heavy metals can still pose a long-term environmental hazard due to bioaccumulation, it is still of vital importance that further reduction or elimination of heavy metals in the sludge be done before land application. 


\subsection{Chemical speciation studies}

The results of the SCE studies for the BMA sludge sample are presented in Figure 1. The percentage of metal extracted in each step of the sequential extraction is presented as a bar diagram. The values represent the average of extraction performed on duplicate samples. As shown, there was a wide variation in the forms of metals present in the sludge sample. Chromium, $\mathrm{Cu}$ and $\mathrm{Ni}$ which seem to predominate in residual fractions, have also some percentage of bound to organic and inorganic phase, and bound to carbonate. For $\mathrm{Cr}$, the residual fraction constitutes $95 \%$ of the metal while the remaining $5 \%$ is bound to organic and inorganic matter form. The residual form for $\mathrm{Cu}$ constitutes $81 \%$ of the metal, followed by bound to organic and inorganic matter (at 14\%), bound to carbonate (at $3 \%$ ) and exchangeable at $2 \%$. For $\mathrm{Ni}$, the residual form constitutes only $29 \%$ of the metal, followed by bound to carbonate (at 22\%), bound to organic and inorganic matter (at 20\%), bound to iron and manganese (at 19\%) and exchangeable at $10 \%$. Lead and $\mathrm{Zn}$ on the other hand, were found mostly in the bound to organic and inorganic matter forms, i.e., in the oxidizable phase, although a high percentage of residual form is also present in $\mathrm{Pb}$ and exchangeable form in $\mathrm{Zn}$. For $\mathrm{Pb}$, bound to organic and inorganic matter form constitutes $60 \%$ of the metal, followed by residual (at $38 \%$ ), bound to iron and manganese and bound to carbonate both at only $1 \%$. Zinc metal contains $44 \%$ bound to organic and inorganic matter, followed by bound to carbonate and bound to iron and manganese, both at $20 \%$, residual form (at $14 \%$ ) and exchangeable form at $3 \%$.

Metals associated with the exchangeable and oxidizable (bound to organic and inorganic matter) phases are easily mobilized by the ion exchange reaction and also by the decomposition and transformation of organic matters and can therefore easily leached out with the acids $[18,19]$. Moreover, metals in the acid extractable phase (or carbonate bound) which are very sensitive to $\mathrm{pH}$ changes are also readily leached when the $\mathrm{pH}$ of the environment is decreased [20] and hence easily extractable from the sludge solution at favorable $\mathrm{pH}$. Residual fraction on the other hand is strongly bound to the sludge matrix.

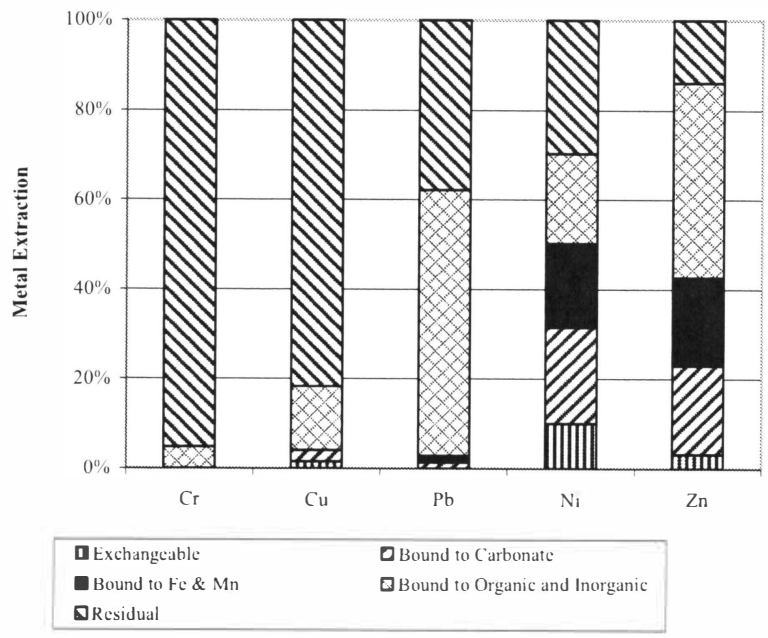

Figure 1. Metal fractionation profile for BMA sludge sample 


\subsection{Characteristics of raw liquid from pineapple wastes}

Table $I$ shows the characteristics of the unfermented, naturally fermented and A. niger fermented raw liquid from pineapple wastes. As can be observed, fructose, glucose and sucrose seemed to be present in the raw liquid which is favorable for the production of citric acid. According to Yigitoglu [7], the usual carbon sources for fermentation to produce high yield of citric acid are glucose, fructose, or sucrose. Moreover, he also quoted that not only the type but also the concentration of the carbon source is important in the citric acid fermentation with $A$. niger, with maximal citric acid production rate achieved at 14 to $22 \%$ of sugar in the medium. The decrease in sugar content in the $A$. niger fermented liquid confirms that fermentation of sugar has taken place to produce more acids. The total acidity indicates the presence of citric acid and all other acids such as malic and ascorbic acids [21] in both the unfermented and fermented liquid. The increase in acidity after fermentation of raw liquid with $A$. niger indicated the production of more citric acid and other acids (Table I). The presence of citric acid as carboxylic acids in the raw liquid has also been confirmed by the result of IR spectroscopy study where carboxylic acid dimers display very broad, intense O-H stretching absorption in the region of 3,300-2,500 $\mathrm{cm}^{-1}$ [22]. Results of HPLC measurements of $A$. niger fermented liquid revealed a citric acid content of $5.34 \mathrm{~g} / \mathrm{L}$ which seemed to be consistent with the findings of Sun [11], in which $5.0-13.6 \mathrm{~g} / \mathrm{L}$ of citric acid were extracted from $A$. niger fermented raw liquid from pineapple wastes depending on the sugar content of the raw liquid.

Table 1. Characteristics of raw and fermented liquid from pineapple wastes

\begin{tabular}{cccc}
\hline Parameters & $\begin{array}{c}\text { Unfermented } \\
\text { liquid }\end{array}$ & $\begin{array}{c}\text { Naturally } \\
\text { fermented liquid }\end{array}$ & $\begin{array}{c}\text { A. } \text { niger } \\
\text { fermented liquid }\end{array}$ \\
\hline Density, kg/L & 1.05 & 1.05 & 1.05 \\
$\mathrm{pH}$ & 4.0 & 3.4 & 3.7 \\
Total Sugare $\%):$ & 12.42 & 4.43 & 2.43 \\
Fructose & 2.20 & 2.0 & $\mathrm{ND}$ \\
Glucose & 2.79 & 2.43 & 2.43 \\
Sucrose & 7.43 & $\mathrm{ND}$ & $\mathrm{ND}$ \\
Maltose & $\mathrm{ND}$ & $\mathrm{ND}$ & $\mathrm{ND}$ \\
Lactose & $\mathrm{ND}$ & $\mathrm{ND}$ & $\mathrm{ND}$ \\
Acidity as Citric acid anhydrous & 0.50 & 0.62 & 4.54 \\
(g/l00g) & & & \\
Citric acid content, g/L & $\mathrm{NA}$ & $\mathrm{NA}$ & 5.34 \\
\hline
\end{tabular}

NDe $=$ Not detected

NAe $=$ Not analyzed

\subsection{Leaching Studies}

\subsubsection{Leaching with commercial citric acid}

For leaching with commercial citric acid, $\mathrm{pH}$ conditions of 3.04, 4.0, 5.01 and 6.0 were used in the study. The overall results of the citric acid leaching study at two hours leaching time is presented in Figure 2 (a). As shown, there was a wide variation of removal efficiencies for all metals at various $\mathrm{pH}$ conditions. It was observed that the highest removal seemed to be attained for $\mathrm{Zn}$ at $66 \%$ followed by Nickel at $56 \%$. Copper removal was at $25 \%$ while $\mathrm{Cr}$ and $\mathrm{Pb}$ removals were very minimal at $15 \%$ and $5 \%$ respectively. 


\subsubsection{Leaching with naturally fermented liquid}

For leaching with naturally fermented liquid, pH conditions of $3.67,3.82,4.02,4.24$ and 4.36 were used in the acid leaching study. The minimum $\mathrm{pH}$ selected was 3.67 since reducing the $\mathrm{pH}$ of the sludge sample further down from $\mathrm{pH} 6.83$ using the naturally fermented liquid $(\mathrm{pH}$ $=3.4$ ), would require a considerable amount of liquid while achieving only a very minimal sludge $\mathrm{pH}$ reduction. Results of leaching with naturally fermented liquid at these $\mathrm{pH}$ conditions for two hours contact time, are presented in Figure 2 (b). As shown, the highest removal of about $92 \%$ was attained at $\mathrm{pH} 3.67$ for $\mathrm{Zn}$ followed by $\mathrm{Ni}$ at $57 \%, \mathrm{Cr}$ at $25 \%$ and $\mathrm{Cu}$ at $17 \%$. Removal for $\mathrm{Pb}$ was undetected at this $\mathrm{pH}$ and other $\mathrm{pH}$ conditions. Good result was also obtained at $\mathrm{pH} 3.82$ for $\mathrm{Zn}$. However, for other $\mathrm{pH}$ conditions, very minimal or no removals were attained for some metals.
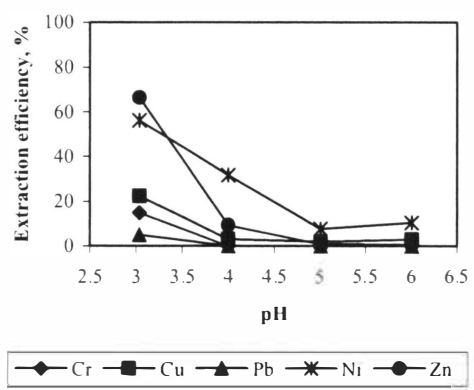

(a)
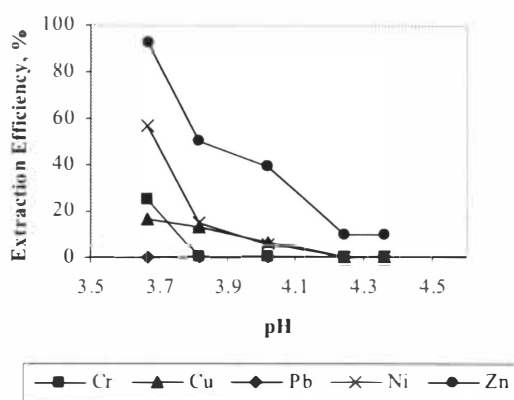

(b)

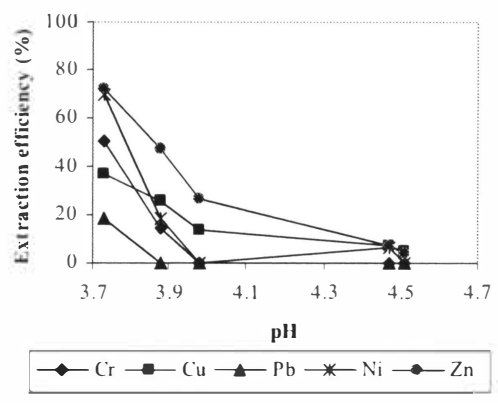

(c)

Figure 2. Metal removal efficiencies by (a) commercial citric acid (b) naturally fermented liquid and (c) A. niger fermented liquid for $\mathrm{Cr}, \mathrm{Cu}, \mathrm{Pb}, \mathrm{Ni}$ and $\mathrm{Zn}$ at various $\mathrm{pH}$ conditions and two hours contact time 


\subsubsection{Leaching with $A$. niger fermented liquid}

For leaching with $A$. niger fermented liquid, $\mathrm{pH}$ conditions of $3.73,3.88,3.98,4.47$ and 4.51 were used in the acid leaching study. The minimum pH selected was 3.73 because reducing the $\mathrm{pH}$ of the sludge sample further down from $\mathrm{pH} 6.83$ using the $A$. niger fermented liquid $(\mathrm{pH}=3.7)$, was found to be not be economically feasible. Results of leaching at these $\mathrm{pH}$ conditions for two hours contact time, are depicted in Figure 2(ce). As shown, the highest removal of about $72 \%$ was attained at $\mathrm{pH} 3.73$ for $\mathrm{Zn}$, followed by $\mathrm{Ni}$ at $70 \%, \mathrm{Cr}$ at $50 \%$ and $\mathrm{Cu}$ at $37 \%$. Removal for $\mathrm{Pb}$ was almost negligible at this $\mathrm{pH}$ and other $\mathrm{pH}$ conditions. Good results were also obtained at $\mathrm{pH} 3.88$ and 3.98 for $\mathrm{Cu}$ and $\mathrm{Zn}$. However, for $\mathrm{pH} 4.47$ and 4.51, very minimal or no removals were attained for some metals.

When comparing the performance of naturally fermented and $A$. niger fermented raw liquid, the latter seemed to give better metal removal efficiency for most metals at lesser liquid requirement. Efficiency is even better than that of citric acid at similar $\mathrm{pH}$ condition. This is maybe due to the production of more citric acid and other acids resulting from the fermentation of raw liquid with $A$. niger.

The forms of metals may have also affected the removal efficiency of the extractants. It was found that $\mathrm{Zn}$ metal seemed to be easily solubilized compared to the other metals, with $\mathrm{Pb}$ being the least soluble. For the BMA sludge sample, the $\mathrm{Zn}$ metal, although predominantly in organic and inorganic form, also contain some percentage of exchangeable and bound to carbonate forms which can easily leached out of the sludge matrix. While the $\mathrm{Pb}$ metal exists in more residual form and therefore strongly bound to the sludge.

\section{CONCLUSIONS}

In general, metal leaching studies seemed to reveal the superiority of $A$. niger fermented liquid over naturally fermented liquid and commercial citric acid in extracting practically all metals studied. At $\mathrm{pH}$ approaching 4, A. niger fermented liquid attained as much as $72 \%$ removal for $\mathrm{Zn}, 70 \%$ for $\mathrm{Ni}, 50 \%$ for $\mathrm{Cr}$ and $37 \%$ for $\mathrm{Cu}$, although effectivity of removal seemed to be less apparent for $\mathrm{Pb}$. The effectivity of removal by $A$. niger fermented liquid may be due to the presence of citric acid and other carboxylic acids as confirmed by the HPLC and IR studies of the fermented liquid.

Variation in metal removal efficiencies may be attributed to the various forms of metals in the sludge. The large amount of solubilization for $\mathrm{Zn}$ is may be due to its predominance as an inorganic precipitate (oxidizable phase) or weakly complexed species, and the presence of exchangeable form of the metal. Nickel and Chromium also exhibited the same properties despite the presence of a high percentage of residual form, which may be due to the chelating properties of the citric acid in fermented liquid. Copper and $\mathrm{Pb}$ on the other hand seemed to be less solubilized compared to other metals due to the presence of a very significant portion of residual form.

\section{ACKNOWLEDGEMENT}

The authors wish to convey their sincere gratitude to the BIOTEC Central Research Unit, Thailand, for their technical assistance and for providing the fungus $A$. niger used in the study. Thanks are also due to the Department of Drainage and Sewerage, Bangkok Metropolitan Administration (BMA), for providing the sludge samples used in this study. 


\section{REFERENCES}

[1] Babel, S., Del Mundo Dacera, D., 2006. Heavy metal from contaminated sludge for land application: A review. Waste Management, 26 (9), 988-1004.

[2] Dutta, S., 2002. Environmental Treatment Technologies for Hazardous and Medical Wastes (Remedial Scope and Efficacy), Tata McGraw-Hill, New Delhi, India.

[3] Veeken, A.H.M., Hamelers, H.V.M., 1999. Removal of heavy metals from sewage sludge by extraction with organic Acids. Wat. Sci. Technol. 40 (1), 129-136.

[4] Del Mundo Dacera, D., Babel, S., 2006. Use of citric acid for heavy metals extraction from contaminated sewage sludge for land application. Water Sci. Technol. 54 (9), 129135.

[5] Marchioretto, M.M., Bruning, H., Loan, N.T.P., Rulkens, W.H., 2002. Heavy metals extraction from anaerobically digested sludge. Water Sci. Technol. 46 (10), 1-8.

[6] Alben, E., Erkmen, O., 2004. Production of citric acid from a new substrate, undersized semolina, by Aspergillus niger. Food Technol. Biotechnol. 42 (1), 19-22.

[7] Yigitoglu, M., 1992e Production of citric acid by fungi. Journal of Islamic Academy of Science, 5 (2), 100-106.

[8] Ali, S., Ul-haq, I., Qadeer, M.A., Iqbal, J., 2002. Production of citric acid by Aspergillus niger using cane molasses in a stirred fermentor. Electronic Journal of Biotechnology $\quad$ ISSN: $07 \mathrm{e} 7-3458 . \quad 5(6)$. http://www.ejbiotechnology. info/content/vol5/issue3/full/3/index.html.

[9] El-Holi, M.A., Al-Delaimy, K.S., 2003. Citric acid production from whey with sugars and additives by Aspergillus niger. African Journal of Biotechnology, 2 (10), 356-359.

[10] Hang, Y.D., Woodams, E.E., 1998. Production of citric acid from corncobs by Aspergillus niger. Biores. Technol. 65, 251-253.

[11] Sun, G., 1984. Production of Citric Acid from Pineapple Waste via Fermentation. Masters Thesis AIT Thesis no. EV-84-16, Asian Institute of Technology, Pathumthani, Thailand.

[12] Food Market Exchange, 2006. Thai pineapple production. Available from http://www.foodmarketexchange.com/datacenter/product/frui..eddc_pi_ft_pineapple030 5. ht.

[13] Tran, C.T., Mitchell, D.A., 1995. Pineapple waste - a novel substance for citric acid production by solid - state fermentation. Biotechnology Letters 17 (10), $1107-1110$.

[14] APHA, AWWA, WEF, 1998. Standard Methods for the Examination of Water and Wastewater, $20^{\text {th }}$ ed. Washington, D.C., U.S.A ISBN: 0-87553-235-7.

[15] American Organization of Agricultural Chemists (AOAC) International, 2000. Official Methods of Analysis of AOAC International, 17th ed., Gaithersburg, MD, USA.

[16] Mcintyre, M., Dynesen, J.,Nielsen, J., 2001. Morphological characterization of Aspergillus nidulans: Growth, septation and fragmentation. Microbiology, 147, 239 246.

[17] AIT, 1998. Feasibility Study in Agricultural Use and Land Application of Sewage and Nightsoil Sludge for Bangkok Metropolitan: Final Report, Thailand.

[18] Shrivastava, S.K., Banerjee, D.K., 1998. Operationally determined speciation of copper and zinc in sewages sludge. Chemical Speciation and Bioavailability, 10 (4), 137-143.

[19] Oake, R., Booker, S., Davis, R., 1984. Fractionation of heavy metals in sewage sludges. Wat. Sci. Technol. 17, 587-598.

[20] Staelens, N., Parkpian, P., Polprasert, P., 2000. Assessment of metal speciation evolution in sewage sludge dewatered in vertical flow reed beds using a sequential extraction scheme, Chemical Speciation and Bioavailabilty, 12 (3), 97-1-7. 
Kalmar ECO-TECH ' 07

KALMAR, SWEDEN, November 26-28, 2007

[21] Chan, H., Chenchin, E., Vonnahme, P., 1973. Nonvolatile acids in pineapple juice. J. Agr. Food Chem. 21 (2), $208-214$.

[22] Silverstein, R., Webster, F., 1998. Spectrometric Identification of Organic Compounds, $6^{\text {th }}$ Ed. John Wiley and Sons, Inc., USA p. 95. 